\title{
FAKTOR RESIKO PENYEBAB PERDARAHAN POSTPARTUM DI PUSKESMAS PAMOTAN KABUPATEN REMBANG
}

\author{
Nurul Ummah $\left.\left.{ }^{1}\right), \operatorname{Ngadiyono}^{2}\right)$, Elisa Ulfiana $\left.{ }^{3}\right)$ \\ e-mail :nurulu1977@gmail.com
}

\begin{abstract}
The Maternal Mortality Rate (AKI) in Indonesia is still high. According to SDKI in 2012 about 359 mothers died for every 100.000 babies born. The direct causes of maternal deaths in Indonesia as well as other countries are bleeding, infection, and eclampsia. From Puskesmas Pamotan's medical data records in 2015 from 437 woman who did labor, 51 of them experienced postpartum hemorrhage.

The purpose of this study are to describe and analyze the factors that causing postpartum hemorrhage, especially in Puskesmas Pamotan. In this study we use analytic research method with retrospective case-control approach. Sampling Technique was used for cases group, while control group used simple random sampling.

The result of this research showed that woman in risk age $(<20$ or $>35$ years old) have 3.7 times greater risk of developing postpartum hemorrhage. Parity at risk ( 1 and > 3) have 2.4 times greater risk of developing postpartum hemorrhage. Pregnant women with anemia $(\mathrm{Hb}<11)$ have 1.8 times greater risk of experiencing postpartum hemorrhage. And prolonged labor have 1.5 times greater risk of experiencing postpartum hemorrhage.

It is sugessted that midwifes need to educate the public about the causes of postpartum hemorrhage. Woman should not be pregnant at too young or too old ages, the pregnant mother should do routine pregnancy checkups, and also give advice to Fertile Age Couples (PUS) to follow the Family Planning program $(\mathrm{KB})$.
\end{abstract}

Keywords: Age, Parity, Anemia, Prolonged Labor, Postpartum Hemorrhage

1), 2, 3): Civitas Akademika dan Dosen Jurusan Kebidanan Semarang

Angka kematian ibu (AKI) di Indonesia masih tinggi. Menurut SDKI tahun 2012 sebesar 359 per 100.000 KH. Penyebab langsung kematian ibu di Indonesia seperti halnya negara lain adalah :perdarahan, infeksi, dan eklampsi (Kemenkes RI, 2014). Perdarahan post partum adalah perdarahan yang terjadi segera setelah persalinan melebihi 500 cc setelah anak lahir. Perdarahan dapat terjadi sebelum atau sesudah lahirnya plasenta (Wiknjosastro, 2009).

Angka kematian ibu (AKI) di Jawa Tengah tahun 2014 sebanyak 126,55 per 100.000 kelahiran hidup, sedangkan di Kabupaten Rembang kasus kematian ibu tahun2015 seba- 
nyak 8 orang, penyebabnya adalah perdarahan post partum sebanyak $37,5 \%$ (3 kasus), eklamsi sebanyak $25 \%$ (2 kasus), emboli air ketuban sebanyak $12,5 \%$ (1 kasus), inversion uteri sebanyak $12,5 \%$ (1kasus), penyakitpenyerta sebanyak $12,5 \%$ (1 kasus ). Data rekam medis Puskesmas Pamotan tahun 2015 jumlah ibu bersalin 437 orang, yang mengalami kejadian perdarahan postpartum 51 orang, 44 orang tertangani di Puskesmas Pamotan, 7 orang di rujuk ke Rumah Sakit untuk mendapatkan penanganan lebih lanjut.

Berdasarkan uraian di atas menggambarkan banyaknya kejadian perdarahan post partum apabila tidak mendapat penanganan tepat bisa timbul komplikasi dan dapat mengakibatkan kematian ibu.Mengingat bahaya yang dapat di timbulkan oleh kejadian perdarahan post partum maka penelitian ini di lakukan untuk mengetahui beberapa faktor resiko penyebab kejadian perdarahan post partum.

\section{TUJUAN PENELITIAN}

Tujuanumum dari penelitian ini adalah untuk mendiskripsikan dan menganalisa faktor resiko penyebab perdarahan post partum di Puskesmas Pamotan .

Sedangkan tujuan khususnya adalah mendiskripsikan dan menganalisa faktor resiko dari umur ibu pada kasus perdarahan post partum, mendiskripsikan dan menganalisa faktor resiko dari paritas ibu pada kasus perdarahan post partum, mendiskripsikan dan menganalisa faktor resiko anemia ibu pada kasus perdarahan post partum, mendiskripsikan dan menganalisa faktor resiko persalinan lama pada kasus perdarahan post partum.

\section{METODE PENELITIAN}

Penelitian ini merupakan jenis penelitian analitik dengan pendekatan retrospektif kasus kontrol.

Populasi dalam penelitian ini adalah semua ibu bersalin diwilayah Puskesmas Pamotan tahun 2015, dengan jumlah sampel 51 orang kelompok kasus dan 51 orang kelompok kontrol.Tehnik pengambilan sampel dengan menggunakan sampling jenuh untuk kelompok kasus,sedangkan untuk kelompok kontrol menggunakan simple random sampling.

Pengumpulan data yang digunakan dalam penelitian ini adalah dengan menggunakan metode dokumentasi. Data yang di kumpulkan berupa data sekunder di peroleh dari catatan medik di Puskesmas Pamotan Kabupaten Rembang tahun 2015. Adapun data yang dikumpulkan antara lain: identitas ibu bersalin dengan perdarahan post partum dan fakor resiko penyebab perdarahan post partum.

Pengumpulan data persiapan yaitu peneliti mengajukan surat ijin penelitian ke prodi DIV Kebidanan Poltekes Kemenkes Semarang, mengajukan ijin penelitian kepada Kepala Kesbanglinmas kabupaten Rembang, BAPEDA kabupaten Rembang dan Dinas Kesehatan Kabupaten Rembang untuk dapat melakukan penelitian di Puskesmas Pamotan .

Setelah mendapat izin, peneliti mengamati catatan medik pasien untuk mendapatkan data yang di peroleh.Setelah di lakukan pengecekan dan pengundian, ada data yang tidak lengkap dan tidak sesuai kriteria inklusi dan ekslusi kemudian di lakukan pengundian lagi sampai didapatkan data yang sesuai kriteria. Kemudian peneliti mencatat data yang di perlukan 
yaitu nama inisial pasien, usia, paritas, anemia dan persalinan lama. Kemudian peneliti mengisi lembar chek list, dimana peneliti memberikan tanda $(\sqrt{ })$ meliputi usia, paritas, anemia, persalin-an lama dari 51 pasien ibu bersalin yang mengalami perdarahan post partum dan 51 pasien ibu bersalin yang tidak mengalami perdarahan post partum berdasarkan catatan medik pasien.

Penelitian ini menggunakan analisa bivariat dengan odd ratio, yaitu suatu rasio perbandingan pajanan diantara kelompok kasus terhadap pajanan pada kelompok kontrol.

\section{HASIL DAN PEMBAHASAN}

\section{Hasil}

Setelah di lakukan penelitian terhadap 51 ibu bersalin yang mengalami perdarahan postpartum dan $51 \mathrm{ibu}$ bersalin yang tidak mengalami perdarahan postpartum di Puskesmas Pamotan Kabupaten Rembang, di dapatkan data yang akan di sajikan dalam bentuk tabel untuk menjelaskan masing - masing faktor. Dari hasil pengolahan data yang telah dilakukan kemudian disajikan dalam bentuk deskriptif maupun analisis besar resiko variabel independen terhadap variabel dependen sebagai berikut :

Umur ibu bersalin

Dari tabel 1 Menjelaskan proporsi umur ibu yang beresiko tinggi ( $<20$ tahun atau $>35$ tahun) lebih besar sebanyak 30 orang $(58,8 \%)$ pada kelompok kasus di banding dengan kelompok kontrol sebanyak 14 orang $(27,5 \%)$. Hal ini menunjukkan bahwa persentase yang mengalami perdarahan postpartum yang beresiko tinggi lebih tinggi dibandingkan yang tidak mengalami perdarahan postpartum pada kelompok umur yang sama ( resiko tinggi). Sedangkan proporsi umur ibu yang tidak beresiko ( $<20$ tahun atau $>35$ tahun) lebih besar sebanyak 37 orang ( $72,5 \%$ ) pada kelompok kontrol di banding dengan kelompok kasus sebanyak 21 orang $(41,2 \%)$. Hal ini menunjukkan bahwa persentase yangtidak mengalami perdarahan postpartum pada usia tidak beresiko lebih tinggi dibandingkan yang mengalami perda-rahan postpartum pada kelompok umur yang sama (tidak beresiko).

Hasil perhitungan Odds Ratio menunjukkan bahwa umur merupakan faktor resiko kejadian perdarahan postpartum, yang artinya umur ibu yang beresiko $(<20$ tahun atau $>35$ tahun) mempunyai resiko 3,7 kali lebih besar untuk terjadi perdarahan postpartum dibandingkan ibu yang berumur tidak beresiko ( 20 - 35 tahun).

Paritas ibu bersalin

Dari tabel 2 Menjelaskan proporsi paritas ibu yang beresiko tinggi (1 atau $>3$ ) lebih besar sebanyak 33 orang $(64,7 \%)$ pada kelompok kasus di banding dengan kelompok kontrol sebanyak 22 orang $(43,1 \%)$. Hal ini menunjukkan bahwa persentase yang mengalami perdarahan postpartum yang beresiko tinggi lebih tinggi disbandingkan yang tidak mengalami perdarahan postpartum pada kelompok paritas yang sama (Resti). Sedangkan proporsi paritas ibu yang tidak beresiko (1 atau >3) lebih besar sebanyak 29 orang ( $56,9 \%$ ) pada kelompok kontrol di banding dengan kelompok kasus sebanyak 18 orang $(35,3 \%)$. Hal ini menunjukkan bahwa persentase yang 
tidak mengalami perdarahan postpartum pada paritas tidak beresiko lebih tinggi dibandingkan yang mengalami perdarahan postpartum pada kelompok paritas yang sama (tidak beresiko).

Hasil perhitungan Odds Ratio menunjukkan bahwa paritas merupakan faktor resiko, dimana besar resikonya adalah 2,4 yang artinya paritas beresiko (1 atau >3)mempunyai resiko 2,4 kali lebih besar untuk mengalami perdarahan postpartum dibandingkan paritas tidak beresiko (2-3).

\section{Anemia}

Dari tabel 3 Menjelaskan proporsi anemia $(\mathrm{Hb}<11)$ lebih besar sebanyak 31 orang $(60,8 \%)$ pada kelompok kasus di banding dengan kelompok kontrol sebanyak 23 orang $(45,1 \%)$. Hal ini menunjukkan bahwa persentase yang mengalami perdarahan postpartum pada anemia lebih tinggi dibandingkan yang tidak mengalami perdarahan postpartum pada kelompok yang sama (anemia).Sedangkan proporsi tidak anemia $(\mathrm{Hb}>11)$ lebih besar sebanyak 28 orang $(54,9 \%)$ pada kelompok kontrol di banding dengan kelompok kasus sebanyak 20 orang $(39,2 \%)$. Hal ini menunjukkan bahwa persentase yang tidak mengalami perdarahan postpartum pada ibu yang tidak anemia lebih tinggi dibandingkan yang mengalami perdarahan postpartum pada kelompok yang sama (tidak anemia).

Hasil perhitungan Odds Ratio menunjukkan bahwa anemia merupakan faktor resiko, dimana besar resikonya adalah 1,8 , yang artinya ibu yang anemia $(\mathrm{Hb}<11)$ mempunyai resiko 1,8 kali lebih besar untuk mengalami perdarahan postpartum dibandingkan ibu yang tidak anemia $(\mathrm{Hb}>11)$
Persalinan Lama

Dari tabel 4 Menjelaskan proporsi persalinan lama lebih besar sebanyak 3 orang $(5,9 \%)$ pada kelompok kasus di banding dengan kelompok kontrol sebanyak 2 orang $(3,9 \%)$. Hal ini menunjukkan bahwa persentase yang mengalami perdarahan postpartum pada persalinan lama lebih tinggi dibandingkan yang tidak mengalami perdarahan postpartum pada kelompok yang sama (persalinan lama).Sedangkan proporsi persalinan normal lebih besar sebanyak 49 orang $(96,1 \%)$ pada kelompok kontrol di banding de-ngan kelompok kasus sebanyak 48 orang ( 94,1\%). Hal ini menunjukkan bahwa persentase yang tidak mengalami perdarahan postpartum pada persalinan normal lebih tinggi dibandingkan yang mengalami perdarahan postpartum pada kelompok yang sama (persalinan normal).

Hasil perhitungan Odds Ratio menunjukkan bahwa persalinan lama (primipara $>24$ jam dan multipara $>18$ jam) merupakan faktor resiko dimana besar resikonya adalah 1,5 yang artinya ibu yang mengalami persalinan lama mempunyai resiko 1,5 kali lebih besar untuk mengalami perdarahan postpartum dibandingkan ibu yang tidak mengalami persalinan lama.

\section{PEMBAHASAN}

Penelitian ini menunjukkan bahwa umur beresiko $(<20$ tahun atau $>35$ tahun)memiliki risiko mengalami perdarahan postpartum 3,7 kali lebih besar dibandingkan ibu yang berumur tidak beresiko (20 sampai 35 tahun). Umur paling aman bagi seorang wanita untuk hamil dan melahirkan adalah umur antara 20 - 35 tahun, karena mereka berada dalam masa reproduksi sehat. 
komplikasi baik medis maupun obstetrik yang dapat membahayakan jiwa ibu, Kematian maternal pada ibu yang hamil dan melahirkan pada umur $<20$ tahun dan umur $>35$ tahun akan meningkatkan secara bermakna, karena mereka terpapar pada sehingga mengapa umur berpengaruh sebagai penyebab perdarahan postpartum. (Manuaba. 2010).

Usia kurang dari 20 th alat reproduksi tidak sehat sehingga sering timbul komplikasi persalinan. Umur lebih dari 35 th tahun berhubungan dengan mulainya terjadi regenerasi sel - sel tubuh terutama dalam hal ini endometrium, akibat usia biologi jaringan dan adanya penyulit pada ibu hamil pada usia 36 tahun ( Cuningham, 2006). Pada usia $<20$ tahun merupakan resiko tinggi kehamilan yang mengancam keselamatan ibu dan bayi hal ini disebabkan pada usia muda organorgan reproduksi dan fungsi fisiologisnya belum optimal secara psikologis belum tercapainya emosi dan kejiwaan yang cukup dewasa sehingga akan berpengaruh terhadap penerimaan kehamilannya yang akhirnya akan berdampak pada proses kehamilan persalinan hingga masa nifas. Ibu dengan usia $<20$ tahun masih berada dalam tahap pertumbuhan dan perkembangan sehingga kondisi hamil akan membuat dirinya harus berbagi dengan janin yang sedang di kandung untuk memenuhi kebutuhan gizinya, rahim dan panggul sering kali belum tumbuh mencapai ukuran dewasa. Sebagai akibatnya pada umur tersebut bila melahirkan bisa mengalami persalinan lama, sehingga beresiko terjadinya perdarahan postpartum. Bila umur diatas 35 tahun kondisi kesehatan sudah menurun sehingga hamil pada umur tersebut mempunyai kemung- kinan lebih besar untuk terjadi persalinan lama dan perdarahan postpartum.

Hasil penelitian ini sesuai dengan penelitian Pardosi, S. (2005) menyimpulkan bahwa ibu hamil dengan umur $<20$ atau >35 tahun memiliki risiko perdarahan postpartum 2,3 kali lebih besar dibandingkan ibu hamil yang dengan umur 20 - 35 tahun.

Penelitian menunjukkan bahwa paritas merupakan faktor resiko, dimana besar resikonya adalah 2,4 yang artinya paritas beresiko (1 atau >3)mempunyai resiko 2,4 kali lebih besar untuk mengalami perdarahan postpar-tum dibandingkan paritas tidak bere-siko (2-3).

Setiap kehamilan rahim mengalami pembesaran, terjadi peregangan otototot rahim. Akibat regangan tersebut elastisitas otot-otot rahim rahim tidak kembali seperti sebelum hamil setelah persalinan. Semakin sering ibu hamil dan melahirkan, semakin dekat jarak kehamilan dan kelahiran, elastisitas uterus semakin terganggu, akibatnya uterus tidak berkontraksi secara sempurna dan mengakibatkan perdarahan postpartum.( Saifudin. 2010)

Hasil penelitian ini sejalan dengan penelitian Purwanti, S. (2014) menyimpulkan bahwa paritas juga berhubungan secara bermakna dengan kejadian perdarahan postpartum. Ibu hamil dengan paritas 1 atau lebih dari 3 memiliki risiko perdarahan postpartum 2,2 kali lebih besar dibandingkan ibu hamil yang dengan paritas 2 sampai 3 .

Penelitianmenunjukkan bahwaanemia merupakan faktor resiko, dimana besar resikonya adalah 1,8 , yang artinya ibu yang anemia $(\mathrm{Hb}<11)$ mempunyai resiko 1,8 kali lebih besar untuk mengalami perdarahan postpar- 
tum dibandingkan ibu yang tidak anemia $(\mathrm{Hb}>11)$

Kekurangan hemoglobin dalam darah dapat menyebabkan komplikasi lebih serius bagi ibu baik dalam kehamilan, persalinan dan nifas. Oksigen yang kurang pada uterus akan menyebabkan otot-otot uterus tidak berkontraksi dengan adekuat sehingga dapat timbul atonia uteri yang mengakibatkan perdarahan postpartum (Manuaba, 2010).

Anemia dapat mengurangi daya tahan tubuh ibu dan meninggikan frekuensi komlipkasi kehamilan serta persalinan. Anemia juga menyebabkan risiko perdarahan pasca persalinan. Penelitian ini sesuai dengan penelitian Dina, D (2013) yang menyatakan bahwa anemia bermakna sebagai faktor risiko yang mempengaruhi perdarahan postpartum. Ibu yang mengalami anemia berisiko 2,9kali mengalami perdarahan postpartum dibanding ibu yangtidak mengalami anemia.

Persalinan lama adalah persalinan yang berlangsug lebih dari 24 jam pada primi, dan lebih dari 18 jam pada multi ( Mochtar, 2012).

Hasil penelitian menunjukkan bahwa persalinan lama merupakan faktor resiko dimana besar resikonya adalah 1,5 yang artinya ibu yang mengalami partus lama mempunyai resiko 1,5 kali lebih besar untuk mengalami perdarahan postpartum dibandingkan ibu yang tidak mengalami persalinan lama.

Mekanisme terjadinya perdarahan pada persalinan lama adalah kelemahan dan kelelahan otot rahim. Bila persalinan berlangsung lama dan terlambat penanganannya dapat menimbulkan trias komplikasi baik terhadap ibu maupun bayi. Pada ibu berupa pendarahan, infeksi dan trauma persalinan, sedangkan pada bayi berupa infeksi, trauma persalinan dan aspiksia sampai kematian janin dalam rahim yang akhirnya menyebabkan angka kematian ibu dan bayi. (Manuaba, 2010). Partuslama disebabkan kontraksi uterus yang tidak adekuat, selain faktor janin dan faktor panggul ibu. Jenis kelainan kontraksi rahim adalah inertia uteri dimana kontraksi rahim lebih singkat dan jarang sehingga tidak menghasilkan penipisan dan pembukaan serviks, serta penurunan bagian terbawah janin, selain inertia uteri kelainan kontraksi lain adalah incoordinat uteri action yaitu tonus otot uterus meningkat di luar kontraksi, tidak ada kordinasi antara kontraksi bagian atas, tengah dan bawah menyebabkan kontraksi tidak efisien dalam mengadakan pembukaan. Persalinan lama dapat menyebabkan kelelahan uterus dimana tonus otot rahim pada saat setelah plasenta lahir uterus tidak dapat berkontraksi dengan baik sehingga terjadi perdarahan postpartum.

Hasil penelitian ini sesuai dengan penelitian Dina, D (2013) menyimpulkan bahwa persalinan lama memiliki resiko 3,5 kali lebih besar untuk mengalami perdarahan postpartum.

\section{KESIMPULAN}

1. Umur beresiko $(<20$ atau $>35$ tahun) memiliki risiko untuk mengalami perdarahan postpartum 3,7lebih besar daripada ibu yang berumur tidak beresiko (20 - 35 tahun).

2. Paritas beresiko ( 1 dan > 3) memiliki risiko 2,4 kali lebih besar untuk mengalami perdarahan postpartum dibandingkan dengan paritas tidak beresiko $(2-3)$.

3. Ibu hamil dengan anemia $(\mathrm{Hb}<11)$ memiliki risiko 1,8 kali lebih besar 
untuk mengalami perdarahan postpartum dibandingkan dengan ibu hamil yang tidak anemia ( $\mathrm{Hb}>11)$.

4. Persalinan lama memiliki risiko untuk mengalami perdarahan postpartum 1,5 kali lebih besar di bandingkan persalinan normal.

\section{SARAN}

1. Bagi Tenaga Kesehatan, diharapkanmemberikan penyuluhan pada masyarakat tentang faktor resiko penyebab perdarahan postpartum antara lain: umur, paritas, anemia, persalinan lama.

2. Bagi masyarakat

a. Ibu tidak hamil pada usia terlalu muda atau terlalu tua.

b. Ibu sebaiknya memeriksakan kehamilannya secara rutin, sehingga bisa mendapatkan informasi tentang dirinya dan kehamilannya agar lebih siap menghadapi persalinan.

c. Ibu juga harus memperhatikan menu seimbang dan minum tablet tambah darah agar tidak mengalami anemia.

d. Menganjurkan ibu untuk melahirkan di pelayanan kesehatan.

e. Menganjurkan PUS ( Pasangan Usia subur ) untuk mengikuti program KB .

3. Bagi penelitian berikutnya perlu diteliti lebih lanjut, dan mendalam tentang faktor resiko penyebab perdarahan post partum dari penyebab selain: umur, paritas, anemia, persalinan lama.

\section{DAFTAR PUSTAKA}

Arikunto, S. (2006). Prosedur Penelitian Suatu Pendekatan Praktek. Jakarta: Rineka Cipta.

Azwar, S. (2012). Metode Penelitian. Yogyakarta: Pustaka Pelajar.

Budiarto, E. (2008). Biostatistika untuk kedokteran dan kesehatan masyarakat. Jakarta: EGC

Badriyah, Sulastri, Sutio Raharjo.(2010). Pengaruh Faktor Resiko Terhadap Perdarahan Ibu Post Partum Di RS Syarifah Rato Ebu Bangkalan.

(digilib.poltekesdepkes.sby.ac.id/ POLTEKES SBY) diakses tanggal 29 Pebruari 2016.

Cuningham, F. Gary, dkk (2006) Obstetri Wiliam. Jakarta. EGC

Depkes RI. (2004). Standar Pelayanan Kebidanan. Jakarta : Depkes RI.

Dinas Kesehatan Kabupaten Rembang (2015). Profil Kesehatan Kabupaten Rembang. Rembang.

Data Rekam medik Puskesmas Pamotan 2015. Rembang

Dina D, ( 2013) . Faktor Determinan Kejadian Perdarahan Post Partum DI RSUD Majene Kabupaten Majene

Hidayat AA. (2011) Metode penelitian kebidanan dan teknik analisis data. Jakarta: Salemba Medika

Manuaba, I.B.G. (2010). Ilmu Kebidanan Penyakit, Kandungan dan Keluarga Berencana Untuk Pendidikan Bidan. Jakarta: EGC. 


\section{$\begin{array}{llll}\text { JURNAL KEBIDANAN Vol.7 No.15 } & \text { April } 2018 & \text { ISSN.2089-7669 }\end{array}$}

Mochtar, R. (2012). Sinopsis Obstetri Jilid I. Jakarta : EGC.

Notoatmodjo, S. (2010). Metodologi Penelitian Kesehatan. Jakarta : Rineka Cipta.

Nursalam, (2008) Konsep dan penerapan metodologi penelitian ilmu keperawatan pedoman skripsi, tesis dan instrumen penelitian keperawatan. Jakarta: Salemba Medika

Pusat data dan informasi profil kesehatan Indonesia 2014. Jakarta: Kementrian Kesehatan RI

Pardosi, M (2005). Analisis FaktorFaktor Yang Berhubungan Dengan Perdarahan Pasca Persalinan dan Upaya Penurunannya di Wilayah Kerja Puskesmas Kota medan Tahun 2005. Tesis. Medan: FKM USU

Purwanti, S (2014). Determinan Faktor Penyebab Kejadian Perdarahan Post Partum Karena Atonia Uteri di RSUD Margono Soekarjo Tahun 2014
Riwidikdo, H.( 2012). Statistik kesehatan.Nuha Medika

Saifuddin, A.B. (2010). Buku Acuan Nasional Pelayanan Kesehatan Maternal dan Neonatal. Jakarta : Yayasan Bina Pustaka Sarwono Prawirohardjo.

Sugiyono. (2010). Statistika Untuk Penelitian. Bandung: Alfabeta.

Sarmini Moedjiarto. Jurnal Hospital Majapahit. 2009

Syafneli, Sri M Daulay (2010) Analisis faktor-faktor yang berhubungn dengan perdarahan post partum primer di RSUD Rokan Hulu ( ejurnal.upp.ac.id/index.php/akbd/a rticle/view/142/143) di akses tanggal 12 Desember 2015

Sujarweni Wiratna.V (2014). Metodologi Penelitian. Yogyakarta: Pustaka Baru

Wiknjosastro, H. (2009). Ilmu Kebidanan. Jakarta: Yayasan Bina Pustaka Sarwono Prawirohardjo. 